\title{
Práticas de inclusão e exclusão como constituição de fronteiras
}

\author{
Constitution of boundaries as practices of \\ inclusion and exclusion
}

\author{
Catrin Heite \\ Marion Pomey \\ Charlotte Spellenberg*
}

\begin{abstract}
Resumo: Fronteiras têm significado simbólico e social, reproduzem desigualdade social através de adscrições moralizantes e geram inclusão ou exclusão de determinadas pessoas ou grupos. Fronteiras - ou a perspectiva analítica sobre elas - são relevantes para a Pedagogia Social porque informam sobre as concepções normativas da ordem social bem como sobre a participação sociopedagógica própria nelas. Ordens sociais normativas traçam fronteiras entre o ser afeito a crises e o dever ser ideal, e produzem realidades sociais. Através de relações fronteiriças assim constituídas entre realidade e possibilidade também é possível reconstruir empiricamente demarcações de fronteiras que geram inclusões e exclusões. Isso é tratado ilustrativamente no texto com relação à atuação prática da Pedagogia Social ao serem reconstituídas ordens sociais normativas de "boa" e de "má" parentalidade. Uma perspectiva analítica de fronteira torna perceptíveis (im)possibilidades do ser (diferente) como exclusões contingentes e normativamente plausibilizadas, e desvela construções sociopedagógicas da realidade juntamente com suas consequências como sendo passíveis de transformação.
\end{abstract}

Palavras-chave: Análise de fronteiras. Fronteiras simbólicas e sociais. Desigualdade social. Inclusão e exclusão normativa. Constituição da realidade. Concepções normativas heterogêneas de parentalidade.

\footnotetext{
* Catrin Heite é doutora em Ciências da Educação com a tese Serviço Social na luta por reconhecimento e livre-docente com a tese Serviço Social e o estado de bem-estar social, ambas pela Universidade de Bielefeld (Alemanha), professora titular no Institut für Erziehungswissenschaft da Universidade de Zurique (Suíça) <c.heite@ife.uzh.ch>; Charlotte Spellenberg é doutora em Pedagogia Social pela Universidade Leuphana (Lüneburg, Alemanha) e professora assistente na Universidade de Zurique <charlotte.spellenberg@ife. uzh.ch>; Marion Pomey é formada em Pedagogia Social e Publicidade pela Universidade de Zurique, onde é doutoranda <mpomey@ife.uzh.ch>. Traduzido do alemão por Emil A. Sobottka.
}

\begin{tabular}{|l|l|l|l|l|l|}
\hline Civitas & Porto Alegre & v. 13 & n. 3 & p. 496-511 & set.-dez. 2013 \\
\hline
\end{tabular}




\begin{abstract}
Boundaries have symbolic and social meaning, reproduce social inequalities via moralizing ascriptions and generate in- and exclusions of specific (groups of) persons. Boundaries resp. a boundary analytic perspective are relevant for Social Work in so far, as they shed light on normative conceptions of order and the own involvement of Social Work within these processes. Normative orders draw boundaries between a critical be and an ideal should-be, they create social realities. By these constituted boundary relations of reality and possibility, empiric boundaries - which create in- and exclusions - can be reconstructed. In the article this is shown exemplarily for the sociopedagogic practice and the normative order of 'good' and 'bad' parenting. Therefore, a boundary analytic perspective makes (im)possibilities of being (different) recognizable as contingent and normatively plausibilized exclusions, it discloses socio-pedagogic constructions of reality with their consequences and workability.
\end{abstract}

Keywords: Boundary analysis. Social inequality. Normative inclusion and exclusion. Constitutions of reality and possibility. Hetero-normative concepts of parenting.

Em La police des familles Jacques Donzelot (1980, p. 82) afirma: "Por isso é necessário encontrar e descobrir em cada busca por ajuda o fracasso moral que em maior ou menor medida lhe subjaz: essa dose de leviandade, preguiça, depravação que se encontra em toda miséria". Em conexão com esse olhar sobre a interpretação do social - e, com isso, também sobre adscrições moralizantes feitas ao público alvo da Pedagogia Social - no texto primeiramente é esboçada uma perspectiva analítica de fronteira, para assim captar práticas de inclusão e exclusão como constituição de fronteiras. Com base nisso é discutida a relação entre demarcações de fronteiras e normatividades para então exercitar isso empiricamente no campo da intervenção em situações de crise na família. ${ }^{1}$ Por fim, busca-se sintetizar o conceito de fronteira como categoria analítica para processos de demarcação de fronteiras e sua importância para a Pedagogia Social.

\title{
Perspectiva analítica de fronteira
}

Com o conceito analítico de fronteira são tratadas questões muito distintas, como por exemplo fronteiras de estados nacionais e de outros espaços, fronteiras culturais, políticas e sociais e, nesse contexto, poder, dominação, desigualdade social, normas, discursos, saberes e produção de saber. A argumentação que segue toma como base uma definição de fronteiras simbólicas e sociais segundo Lamont e Molnár (2002, p. 168):

1 Este texto surgiu de discussões conjuntas e foi apresentado em partes individuais na Conferência de Pedagogia Social de 2013 em Tübingen, Alemanha. Essas partes refletem a ênfase em pesquisa de cada autora e por isso foram escritas individualmente: perspectiva analítica de fronteira, por Catrin Heite; normatividade, por Charlotte Spellenberg; fronteira empírica: intervenção em situação de crise, por Marion Pomey. 
Symbolic boundaries are conceptual distinctions made by social actors to categorize objects, people, practices, and even time and space. They are tools by which individuals and groups struggle over and come to agree upon definitions of reality. Examining them allows us to capture the dynamic dimensions of social relations, as groups compete in the production, diffusion, and institutionalization of alternative systems and principles of classifications. [...] They are an essential medium through which people acquire status and monopolize resources. Social boundaries are objectified forms of social differences manifested in unequal access to and unequal distribution of resources (material and nonmaterial) and social opportunities.

Segundo esses autores, fronteiras simbólicas servem para categorizar coisas, pessoas e práticas. Elas servem à compreensão daquilo que é, que deveria ser e que não deveria ser. Portanto, as fronteiras simbólicas delimitam o normal e o desviante, aquilo que é digno daquilo que não é digno de reconhecimento. Fronteiras simbólicas são traçadas discursivamente por exemplo com categorias como leviandade, preguiça, depravação. Essas fronteiras simbólicas são normativas e podem ser percebidas empiricamente.

Se seguirmos a definição de Lamont e Molnár, as fronteiras sociais são a consequência objetiva ou materializada de fronteiras simbólicas, portanto, acesso desigual a bens materiais e a outros recursos valorizados como formação, participação política e certas formas de vida.

A perspectiva que enfoca fronteiras simbólicas e sociais apoia analiticamente a investigação de estruturas e condições sociais porque enfoca desigualdades, relações de poder e posições sociais bem como práticas (discursivas) de inclusão e exclusão. Assim, fronteiras servem para a invenção e defesa de hierarquias; elas estruturam, impedem, limitam e provocam o agir humano; elas incluem e excluem. Como instâncias simbólicas, territoriais, políticas, normativas e sociais, elas praticamente colocam as coisas "a limpo", isto é, "a fronteira" demarca as concepções sociais de ordem, o dualismo do possível e do impossível, do aceitável e do inaceitável, normal e desviante, do próprio e do alheio, do pertinente e do não pertinente. A fronteira classifica, ordena, normatiza, inclui e exclui; ela privilegia ou desprivilegia, atribui direitos ou os denega; a fronteira é expressão de relações de poder e dominação, e um meio para sua conservação.

Uma área na qual isso tudo desempenha um papel importante é a "área social", a "questão social". Como área de atuação da Pedagogia Social, - como ciência e como profissão - essa perspectiva de análise de fronteiras é aqui esboçada com vistas às fronteiras do social e do sociopedagógico. Pois através 
da fronteira simbólica determinados grupos são marcados como exteriores ao normal, aceitável e bom, e com isso são tornados público-alvo da Pedagogia Social. Desde a formulação original da questão social no século 19 e da invenção de técnicas, métodos e procedimentos para tratá-la, essas categorias, essas adscrições normativas que Jacques Donzelot abarca com leviandade, preguiça e depravação estão presentes; elas podem ser complementadas com categorias e adscrições - histórica e atualmente virulentas - como indisciplina, baixa escolaridade, negligência, falta de espírito empreendedor, dependência de benefícios sociais, consumo problemático de mídia, de tabaco e álcool, jogos de azar, pouca competência para educar e negligência com os filhos. ${ }^{2}$

O discurso histórico e atual sobre aqueles grupos de pessoas que perfazem o núcleo duro da questão social - desempregados, "maus pais", crianças "com problemas comportamentais", "juventude desviada", "famílias com baixa escolaridade", pessoas que "dependem" de políticas sociais - coloca esses grupos fora das fronteiras da normalidade. Pelo fato de essas pessoas que são objeto dos discursos parecerem viver nas margens da normalidade, elas suscitam a questão social. Elas são pauta das discussões como grupos cuja maneira de conduzir a vida, cuja condição moral, cujo caráter não corresponde às normas sociais e por isso devem ser novamente empurrados para dentro da fronteira - dentre outros, também com recursos pedagógicos - com medidas destinadas a dar iniciativa aos desempregados, normalizar "jovens desviados" e facilitar aos "maus" pais a aquisição de competências educacionais.

Porque são vistos como ameaças à ordem social, como perigo para a convivência social, eles são submetidos a esses discursos moralizantes e de desprezo - a preguiça e degeneração daqueles que se encontram fora das fronteiras de uma condução aceitável da vida. Tal como coloca Robert Castel (2008), a questão social trata de processos de desqualificação social, de vulnerabilidade, de desacoplamento e de desprezo. Como definição central da fronteira nesse caso Castel analisa a distinção entre pobres aptos e inaptos para o trabalho. Essa distinção, essa demarcação da fronteira entre pobres bons e maus, desloca para as margens do social aquelas pessoas que poderiam trabalhar mas não o fazem. Aqui elas vagueiam pelas fronteiras simbólicas que são traçadas com relação a estar estabelecido com residência fixa, estar inserido em relações sociais primárias e participar de trabalho legal.

Isso significa que, historicamente, o pedinte apto a trabalhar e, hoje, aquela pessoa a quem se atribui baixa empregabilidade se encontram nessa

\footnotetext{
Mais adiante trataremos da "boa" e da "má" parentalidade e das adscrições normativas correspondentes.
} 
fronteira: não trabalham, não estão ou estão só insuficientemente inseridos em relações sociais primárias. Elas são pedintes ou vivem, eventualmente de forma "abusiva", dos benefícios de políticas sociais supostamente muito generosas e fomentadoras da passividade. As fronteiras simbólicas traçadas com categorias como residência fixa, territorialidade, relações sociais primárias, subsidiariedade, comunidades solidárias informais bem como trabalho formal, diligência, disciplina ou empregabilidade colocam no escanteio todos aqueles que não correspondem a essas expressões do dever ser. Elas marcam normativamente sua condução da vida como inaceitável, como anormal, e os transformam em grupos a serem extirpados, pedagogizados, disciplinados, moralizados, normalizados. Pois as pessoas e classes que vivem nas margens - historicamente eram os vagabundos, o proletariado industrial empobrecido ou o desempregado, enquanto hoje são os jovens tidos como com baixa empregabilidade ou os pais de quem se julga que não tenham competência suficiente para educar seus filhos - essas pessoas são confrontadas com medidas de assistência, apoio, reintegração, mas também com medidas repressivas, moralizantes e disciplinadoras. Trata-se, pois, de pessoas cuja necessidade de apoio não é - ou pelo menos não é prioritariamente - material; ela é verbalizada como moral. Segundo essa concepção, tratase acima de tudo de um problema de caráter e da condução da vida ou de concepção de vida, e com isso, na lógica da intervenção, as necessidades se enquadram no âmbito das medidas sociopedagógicas. Este discurso sobre os destinatários da Pedagogia Social se revela como demarcação de fronteiras normativas através das quais as teorias sociopedagógicas produzem realidades supostamente em crise e modos de vida tidos como problemáticos.

\section{Normatividade}

A normatividade ocupa um lugar específico nas reivindicações imperativas sociopedagógicas de inclusão e exclusão bem como na formação de consensos sobre "definitions of reality" (Lamont e Molnár, 2002, p. 168). Se a fronteira for concebida sobretudo segundo seus atributos de conectividade e menos como separação, destacando-se a possibilidade de ela ser deslocada, então se revela como a realidade é produzida como um ser-assim somente pelo acesso teórico e pelo seu envolvimento com a normatividade. $\mathrm{O}$ ato de postular um ser-assim contém uma relação de fronteira entre realidade e possibilidade que conecta os dois lados e que não pode ser dissolvida em polos quase fixos, claramente separáveis: a determinação de uma realidade sempre aponta para uma não-realidade. Por meio dessa relação de fronteira e mediante a referência 
a ordens normativas são negociadas diferentes possibilidades de modos de ser, passíveis de reconhecimento.

Ordens normativas produzem fonteiras ${ }^{3}$ por exemplo ao tornar plausível e caracterizar certos modos de ser como (i)legítimos. Com isso o aspecto normativo destas demarcações de fronteira, destas práticas de inclusão e exclusão de modos possíveis de ser, pode ser captado através da observação das estratégias de plausibilização, nas quais a normatividade incide como "uma espécie de amarra sem grilhões" (Forst e Günther, 2011, p. 11) e fornece razões plausíveis. "Ordens normativas repousam sobre justificações basilares e por conseguinte servem para a justificação de regras, normas e instituições sociais. Elas fundamentam reivindicações de dominação e determinadas formas de distribuição de bens e de oportunidades de vida" (Forst e Günther, 2011, p. 11). Destas referências de justificação as razões normativas extraem sua reivindicação de validade e obrigatoriedade. $\mathrm{O}$ caráter normativo das fronteiras simbólicas e sociais consiste, pois, no modo como elas fornecem razões dotadas de obrigatoriedade que pareçam plausíveis e dignas de reconhecimento.

Uma importância central da normatividade se revela em que, dentro de determinada ordem normativa, as razões justificadoras parecem como um fato, como "uma circunstância cuja existência se aceita e não questiona" (Forst e Günther, 2011, p. 18). Quase não é mais perceptível o caráter construído e questionável das razões. Assim exitem determinadas constelações de ação que podem ser definidas como casos sociopedagógicos e contar com alta probabilidade de concordância intersubjetiva. Concordância a respeito de que neste contexto de ação há um conteúdo problemático a ser tratado, e que ele pode ou deve ser percebido como da alçada da Pedagogia Social (Schäfer, 1989). Trata-se, pois, de um horizonte normativo, de uma ordem de justificação que se torna atuante nesse caso; essa ordem de justificação torna provável a concordância intersubjetiva na medida em que pela normatividade ela vincula a razões plausíveis e obrigatórias.

3 A relação entre ordens normativas, fronteiras e o papel da Pedagogia Social deve ser vista como um entrelaçamento: de um lado, ordens normativas produzem fronteiras. Assim propostas pedagógicas podem ser tomadas plausíveis mediante o recurso à normatividade. As ordens normativas, com isso, servem como justificações ao ajudarem as propostas sociopedagógicas de realidade a alcançarem validade. Por outro lado, a própria Pedagogia Social, ao traçar a fronteira entre ser e dever-ser também produz ordens normativas.

4 "Se deste modo normatividade tiver relação com razões, então as normas podem ser compreendidas como princípios que indicam de modo substancial quais razões as pessoas têm para fazer algo ou crer em algo" (Wallace, 2011, p. 34). Normas epistêmicas prescrevem então o que deve valer como evidência para a verdade, normas práticas indicam as razões que os agentes têm para certas ações. 
Através de acessos normativos que reafirmam fatos, desigualdades são (re)produzidas por meio de inclusões e exclusões. Aquilo que é incluído ou excluído são, por exemplo, determinados modos de vida, modos de ser e se comportar definidos como ilegítimos e possibilidades de ser diferente. Através do entrelaçamento com normatividade se oculta como a demarcação de fronteiras está conectada à regulação contingente daquilo que é produzido como um modo de ser inteligível e o que não é (cf. Butler, 1997, p. 262).

O papel da Pedagogia Social se revela aqui tanto ao, em seu acesso teórico às realidades, trabalhar os limites das possibilidades de se ver e verbalizar modos de ser como ao dar forma às fronteira entre aqueles modos de ser definidos como problemáticos e ao expressar quais mudanças são ou devem ser tidas como factíveis. Faz diferença se nesse contexto se concebe o ser e o dever-ser no sentido de uma relação de diferenças ou se realidade e possibilidade são concebidas como uma relação de fronteiras entrelaçadas.

A Pedagogia Social trabalha com a relação problemática entre ser e dever-ser. Dentro de sua reconstrução dessa relação, ela tende a argumentar reativamente por exemplo ao tomar crises como fatos dados. Estes diagnósticos de época, como formula Dollinger (2008), em caso de sucesso dão legitimidade à Pedagogia Social - e justamente esse sucesso, no sentido de produção de concordância intersubjetiva, depende decisivamente do recurso a ordens normativas.

Enquanto a diluição das fronteiras entre aquilo que é e o que poderia ser é tido como condição de qualidade da Pedagogia Social, poderia surgir a impressão que ela age como não participante, a partir de um lugar exterior, a partir do qual ela poderia colocar à disposição um contra-saber ou um contraagir sociopedagógico. Com isso se mascara a perspectiva sobre a própria Pedagogia Social, que inclui e exclui enquanto uma participante da demarcação de fronteiras e com um papel importante na constituição discursiva das condições sociais de vida. Pois a Pedagogia Social não está isenta de interesses normativos próprios e seu poder de ação vai além da simples explicitação de problemas e de possibilidades adequadas de intervenção.

Quando pressupostos objetivistas de crise constituem a base argumentativa para exigências sociopedagógicas, então se evoca uma diferença polarizadora entre um ser em crise e um dever-ser ideal. Com base em sua normatividade, tais diferenciações permitem afirmar um ser e um dever-ser plausíveis: aqui o ser marcado como problemático e relevante para a Pedagogia Social; lá o dever-ser legítima e plausivelmente digno de ser aspirado. O ser e o dever-ser são aqui pressupostos afirmativamente como polos fixos, embora eles sejam constituídos por práticas de inclusão e exclusão e, em perspectiva crítico- 
discursiva, sequer podem ser determinados claramente. De qualquer modo é impossível recorrer a algum critério objetivo para a validade teórica de uma intervenção sociopedagógica sobre a realidade. Aquilo que é sociopedagógico ou quando subsiste uma necessidade de intervenção sociopedagógica não é uma questão que pudesse ser decidida a partir de uma observação empírica independente. Os projetos sociopedagógicos de realidade são contingentes, relacionais e precisam ser afirmados frente aos outros - inseridos em ordens normativas de justificação eles são objetivados e plausibilizados.

Se a realidade fosse afirmada perante a possibilidade de tal modo que parecesse uma fronteira do possível, então através de um recurso ao possível o ser seria confinado de modo radical em suas fronteiras. Se, ao contrário, face a uma realidade supostamente óbvia, a possibilidade fosse afirmada "mediante a ênfase na abertura do futuro, realçando que o presente pode ser percebido de vários modos distintos, que qualquer tentativa de determinação por realidades como tais não fizesse justiça ao espaço de liberdade do sujeito" (Schäfer, 2012, p. 670), então a gente se entregaria a uma contingência infinita dos fatos.

Com isso fica claro que o que está em questão é o ser e sua relação com o dever-ser e que nem uma realidade objetiva nem uma possibilidade pura podem ser evocadas como verdade para resolver esse conflito através de uma relação de diferenças supostamente óbvia. Ao invés disso, realidade e possibilidade poderiam ser concebidas como relação de fronteiras, a saber, seguindo Alfred Schäfer (2012), na forma de um espaço de possibilidades: assim ambas não se contrapõem como entidades soltas e distintas, mas estão entrelaçadas pela fronteira. Com o recurso a este tipo de espaço de possibilidades não se destacaria mais uma diferença opositora como relevante, mas precisamente o entrelaçamento, que torna simplesmente impossível uma diferenciação unívoca. Se a realidade só pode ser apreendida face a sua possibilidade, a sua contingência, então essa relação de fronteiras representa um espaço de possibilidades no qual a realidade sempre será apenas uma das diversas possibilidades. Essa relação de fronteiras entrelaçadas representa a "questionabilidade do real" (Schäfer, 2012, p. 229) que ao mesmo tempo limita realisticamente o espaço do possível. Essas limitações se revelam através de fronteiras simbólicas inclusivas e excludentes na medida em que determinadas possibilidades são reservadas apenas a determinadas pessoas ou grupos de pessoas.

Se a realidade sociopedagógica depende do acesso teórico e de concepções normativas, então aquilo que numa situação determinada é relevante para a Pedagogia Social e o que é válido como sua resposta é objeto de processos de negociação e de demarcações de fronteiras. Maneiras de ser e de se comportar 
não são em si e indiscutivelmente problemáticas ou exigem um tratamento sociopedagógico; necessárias são demarcações normativas de fronteiras e sua fundamentação. Por conseguinte, como procedimento normativo, o agir sociopedagógico tem implicações constitutivas e excludentes em seu acesso à realidade. A esfera da constituição de um tema, a esfera do ser que se quer tratar faz parte da determinação daquilo que tem relevância para a Pedagogia Social: do captar categoricamente a realidade sociopedagógica. Na perspectiva da normatividade isso significa uma unidade interpretativa entre definição e justificação.

A perspectiva analítica das fronteiras se revela como um ganho em conhecimento ao romper com polarizações, tornando possível reconstruir seus entrelaçamentos e, bem especificamente, sua imbricação em justificações normativas. No processo de reconstrução torna-se por conseguinte necessário voltar àquele ponto em que a relação de fronteira construída entre realidade e possibilidade foi transformada em diferenças polarizadoras; torna-se necessário retornar àquele ponto em que plausibilizações normativas e objetificantes proclamam fatos. Assim, a questão não é apenas perguntar que tipo específico de atributos um modo de ser problemático revela e como ele poderia ser ajudado; mais que isso, é possível esclarecer quais condições, interesses, aspirações de normalidade e concepções de sujeito são acionados nesse diagnóstico. Sendo assim, o objetivo deixaria de ser a pergunta pela ralidade correta ou falsa, e passaria a ser a pergunta pela gênese e pelo próprio papel da Pedagogia Social nela.

A fronteira como categoria analítica se revela como o elemento de ligação e ao mesmo tempo como constitutiva da possibilidade de questionar o real e o possível. Para o estudo sociopedagógico de desigualdades isso implica na necessidade de analisar quais as demarcações de fronteira que são construídas ou evocadas para fazer afirmações adscritivas sobre o ser. Pois plausibilizações normativas justificadoras e justificadas daquilo que atualmente é visível e verbalizável podem ser concebidas como delimitações do ser. Por isso estas estratégias de plausibilização necessitam ser reconstruídas e construídas sempre de novo. Nada precisa ser como é e por isso se coloca a questão, nunca passível de resposta definitiva, como poderia ou deveria ser diferente. As respostas sociopedagógicas a essa questão precisam ser entendidas como processos de demarcação normativa de fronteiras, como constituições do espaço de possibilidades - constituições que, como fechamento desse espaço como sendo a realidade sempre permanecem provisórias, precárias e modificáveis. A teoria da Pedagogia Social por conseguinte não opera simplesmente como reação face a essas tentativas de fechamento que ela encontra. Ela própria 
participa dessas tentativas de fechamento, assim que o tratamento que ela faz das desigualdades não pode ser situado fora das respectivas fronteiras traçadas em cada situação específica. E ao mesmo tempo é uma de suas tarefas desvelar as fronteiras como sendo passíveis de deslocamento e tornar possíveis esses deslocamentos.

\section{A fronteira vista empiricamente: intervenção em situações de crise}

O Serviço Social, como uma "instituição processadora de crises" (Dollinger, 2004, p. 382), traça ele próprio fronteiras através da "interpretação conjunta de realidades sociais" (ibid., p. 383), enquanto define situações como estando em crise. Quais situações de vida devem ser vistas como vulneráveis e passíveis de intervenção torna-se visível por exemplo no marco da intervenção sociopedagógica em crises que ameaçam o bem-estar da criança ou do jovem. $\mathrm{Na}$ reconstrução das práticas sociais se revela que - tal como na pesquisa feita por Richter sobre a assistência sociopedagógica às famílias - o marco institucional é estruturado a partir de um "ideal da família burguesa nuclear, (hétero)normativa e sexualmente codificada, como 'padrão de medida' e como referência para orientação e comparações” (Richter, 2013, p. 15). Desse modo formam-se normas sobre a "boa" educação que, por essa idealização da família nuclear burguesa, simultaneamente rebaixam as famílias distantes deste ideal (Richter, 2013, p. 16). Nas reflexões de Dollinger sobre a teoria da crise do Serviço Social se revela que a intervenção destinada a superar o problema se embasa exatamente "naquelas orientações normativas que são estabelecidas na definição da crise" (Dollinger, 2004, p. 393). A breve análise dos dados que se segue não revelará tanto o ideal da família nuclear burguesa, mas antes o processo de demarcação de fronteiras na constituição dos destinatários do Serviço Social como "bons" ou "maus" pais.

As fronteiras normativas, constituídas durante a práxis sociopedagógica, podem ser reconstruídas por exemplo através da descrição de casos. Apoiandose em estudos de Star e Griesemer (1989, p. 393), Klatetzki (2013, p. 118) vê "as descrições de caso no Serviço Social como objetos limítrofes idealtípicos" que estabelecem uma ligação entre diferentes campos de atuação, pois "they have different meanings in different social worlds but their structure is common enough to more than one world to make them recognizable". Nesse sentido os episódios relatados a seguir, extraídos do material empírico, podem ser vistos como fragmentos de um relato de caso que transita entre os dois campos de atuação: intervenção em situações de crise e instituição responsável pela política social. 
Com base no material empírico resultante de um ano de observação etnográfica de uma intervenção sociopedagógica numa situação de crise pretende-se mostrar como a parentalidade é negociada e quais as fronteiras que explícita ou implicitamente estão entrelaçadas nela. Objeto da análise será o modo como pela ação sociopedagógica são traçadas fronteiras e como, ao serem estabelecidas relações entre o dever-ser-assim e o não-dever-ser-assim, se constitui a Pedagogia Social. A demarcação da fronteira entre um ser em crise e um dever-ser idealizado se adensa no material empírico ao longo da fronteira entre a "boa" e a "má" parentalidade. Com isso a fronteira se torna categoria de análise de práticas de tomada de decisão e de legitimação.

A base empírica vem de um relatório sobre Ana, uma menina de 4 anos, que contém informações sobre o acompanhamento durante o período em que ela estava sob tutela. O relatório foi feito perto do final do período da intervenção sociopedagógica, e tem como pano de fundo as negociações sobre (e a legitimação da) futura guarda da criança. Os excertos escolhidos revelam com particular clareza a constituição de fronteiras em relação à parentalidade.

Num primeiro excerto é descrito genericamente, na forma de uma afirmação sociopedagógica profissional, como são tratados casos de intervenção sociopedagógica em situações de crise com vistas à proteção de crianças:

Nós tentamos evitar que o contato entre a criança e sua pessoa de referência primária seja interrompido. Aos pais deve ser dada desde o início a possibilidade de visitarem regularmente sua filha ou filho ou de manterem contato com ela por telefone. No caso de crianças pequenas são esperados contatos diários.

Trata-se da reivindicação normativa de não deixar interromper-se o contato e da questão, se os pais podem ou não cumpri-la. Isso sugere uma postura mais passiva dos profissionais. No cumprimento da tarefa de não deixar o contato ser interrompido, eles dependem das pessoas de referência primária. Mesmo assim, essa tarefa é implicitamente formulada como um indicador de sucesso da intervenção na situação de crise, o que ao mesmo tempo aponta para a necessidade de uma atuação "produtiva" junto com os pais. Nada é dito sobre a qualidade ou o conteúdo desse contato. Trata-se da tentativa de manter ativo "um contato, qualquer que seja". O fato de não ser discutido como deve ser o conteúdo desse contato sugere o pressuposto de que qualquer contato da pessoa de referência primária com a criança seja considerado importante. Nesta formulação, as concepções normativas são reproduzidas basicamente sem questionar e vazias de conteúdo. Também é possível perguntar para quem as tentativas de contato são importantes. Para os profissionais, para as pessoas 
de referência primária ou para a criança? Implícito está um pressuposto: não importa como é a qualidade desse contato, ele sempre é muito importante para a criança e, por extensão, para o bem-estar da criança. O pressuposto segundo o qual o contato entre a criança e as pessoas de referência primária deva ser fomentado e que dentro do possível se deva tentar evitar que ele se interrompa leva, ao mesmo tempo, a uma imunização face a uma possível postura crítica frente a aspectos da parentalidade que possam colocar o bem-estar da criança em risco. Poder-se-ia dizer que se trata de uma idealização da parentalidade e simultaneamente de uma tabuização dos riscos ao bem-estar da criança e de uma reiterada encenação da falta de autonomia da criança. À criança não é dada a possibilidade de se esquivar desse contato; tendo esse estatuto normativo como pano de fundo, a criança não pode participar da decisão sobre o contato com as suas pessoas de referência primária e sua perspectiva é excluída nessa situação. Parece que aqui não se trata em primeiro lugar da proteção da criança ou de seu bem-estar, mas sobretudo do cumprimento de um invólucro normativo vazio chamado manutenção ativa do contato. Uma fronteira é traçada entre pais e criança, onde os pais são construídos como ativos e a criança como passiva; a ela é negada a liberdade de escolher, ela desaparece. Através da subjetivação dos pais, a quem é delegada a decisão, possivelmente a criança é objetivada. Além disso é traçada uma fronteira hierarquizante entre pessoas de referência primária e secundária, pois se existem pessoas de referência primária, então devem existir também as de referência secundária. Também é perceptível uma atribuição de responsabilidade aos pais; a responsabilidade dos profissionais, portanto, consistiria na convocação para que sejam asseguradas as condições (ou seja: facilitar as possibilidades de contato), não a garantia mesma dessas condições.

Sobre a mãe consta no relatório:

Ainda que tivéssemos nos esforçado, não conseguimos estabelecer contato com a mãe. A mãe sabia onde sua filha estava, mas nunca tomou a iniciativa de querer vê-la ali. Durante o período da intervenção, Ana encontrou a mãe algumas vezes em finais de semana, que ela passava com o pai ou com a avó materna. O repentino rompimento da relação no final do ano nós avaliamos como experiência traumática para Ana. De vez em quando, mas em especial no início, ela perguntava pela mãe.

No trecho transparece uma espécie de orgulho profissional ferido. Com relação à mãe, os argumentos são moralizantes e normativos. Ela é implicitamente acusada de não ter tentado querer. Implicitamente está aí 
contida a concepção que uma mãe deve saber onde sua filha está, que ela deve querer ver sua filha e que também deve tomar a iniciativa de tentar vê-la. $\mathrm{O}$ rompimento da relação no final do ano, portanto pouco antes da perda da tutela, avaliado como traumático, reforça um juízo moralizante. Segundo o que segue na descrição, a criança vez ou outra pediu pela mãe, em especial no início. Aqui se revela a construção normativa-moral de uma mãe e o deslocamento da responsabilidade dos profissionais para essa mãe, que deveria saber, querer e tomar iniciativa.

Sobre o pai consta no relatório:

Durante todo o período o pai foi uma pessoa de referência firme e confiável. [...] Referindo-se às primeiras sessões, o pai sempre de novo foi enfático em afirmar como organizaria sua vida em sintonia com as necessidades de Ana. [...] Mas acabou se revelando que nem ele nem o entorno familiar conseguiam cumprir as condições colocadas para que Ana pudesse ser cuidada por eles. Se bem que verbalmente o pai assegurava estar disposto a tudo, mas quando se tratava da concretização dos propósitos, nada acontecia. [...] A cooperação com o pai foi agradável e livre de conflitos. Ele aceitava tudo e não se opunha a nada.

Ainda que no início o pai seja introduzido como uma pessoa de referência firme e confiável, no material que segue justamente esta confiabilidade pode ser desconstruída com relação a sua filha. Isso suscita a questão, para quem o pai era uma pessoa de referência firme e confiável. Parece que o fato de manter contato é tido como suficiente para ser confiável, e a cooperação "agradável, livre de conflitos e sem se opor a nada" por parte do pai faz com que ele seja para os profissionais o interlocutor confiável, que a nada se opõe. Deixando de lado o modo questionável como os profissionais avaliaram a situação, que aqui não será aprofundado, entre os pais é traçada uma fronteira: o pai tornase uma pessoa "boa" de referência também ou justamente porque a mãe não pode ser contactada, mesmo que os profissionais tenham se esforçado. Isso reforça a importância da função do pai como interlocutor para a instituição. Através da exclusão da mãe como "boa mãe" nesse caso o pai é incluído como "pessoa de referência confiável", e com isso como "bom pai". A construção de parentalidade anda de mãos dadas com diversas construções normativas e morais de fronteiras. Com Meissner (2012, p. 17), moral pode ser compreendida como "uma orientação que abrange as atividades institucionais do Serviço Social" enquanto sua tematização explícita tem por objetivo tanto constituir e assegurar cooperação e disciplinamento, como demarcar aqueles comportamentos que contradizem as expectativas institucionais. "Nesse caso 
a responsabilidade pelo respectivo comportamento é explicitamente atribuída à pessoa. A essa situação subjaz a concepção de um 'bom' cliente, que com seu comportamento apoia as intenções dos profissionais” (Meissner, 2012, p. 18). Essa figura argumentativa pode ser encontrada na construção do pai como "bom" pai, como pessoa confiável para os profissionais.

Sumariamente pode ser dito: dentro das fronteiras estão contidos a parentalidade biológica e ativa bem como pessoas de referência primária, o invólucro normativo da manutenção de contatos, a quantidade dos contatos (estar ausente é um critério fundamental), a inclusão do pai como presente, confiável e disponível, a manutenção da família nuclear bem como a idealização da parentalidade. Fora da linha de fronteira se encontram a parentalidade social como pessoas de referência secundária, a qualidade da relação (em oposição à quantidade), a exclusão da mãe como ausente, não confiável e indisponível, bem como a exclusão da criança e de sua perspectiva, uma imunização das ameaças ao bem-estar da criança, acompanhada de um desestímulo da criança e de um deslocamento da responsabilidade dos profissionais para os pais. As estratégias de legitimação introduzidas aqui como demarcações de fronteiras podem ser encontradas no material empírico como ordens normativas, como fundamentações estruturadas que se condensam como justificação de estruturas institucionais, como neste caso na forma de uma intervenção sociopedagógica em situação de crise.

\section{Conclusão}

Em seu significado simbólico e social, o conceito de fronteira se revela como uma perspectiva produtiva para a análise sociopedagógica bem como para o tratamento profissional de desigualdades. Pois através de uma perspectiva de análise de fronteiras assim concebida é possível evidenciar a normatividade das demarcações sociopedagógicas de fronteiras em sua efetividade teóricoepistemológica e empírica: categorizações sociopedagógicas através de fronteiras simbólicas bem como o tratamento de suas consequências no nível das fronteiras sociais estão inseridos em ordens normativas ao mesmo tempo que geram essas ordens. Na reconstrução empírica essas demarcações de fronteiras se revelam na forma de fundamentações para as intervenções sociopedagógicas aceitas como plausíveis. Essas narrativas justificadoras ou estratégias de legitimação tornam-se relevantes para a ação e ao mesmo tempo constituem realidades sociais na forma de relações de fronteira. Em especial os pressupostos constitutivos da Pedagogia Social sobre a "boa conduta de vida", como por exemplo as concepções normativas sobre "boa" educação, "boa" infância, "boa" família e parentalidade etc., correlacionam com formas 
específicas de tratamento profissional de casos sociopedagógicos. Ao lado da reflexão sobre a participação própria, como cientistas e como profissionais, na demarcação de fronteiras é pois tarefa da Pedagogia Social desvelar as fronteiras como passíveis de serem deslocadas e de assumir como perspectiva do Serviço Social sua vocação de trabalhar com essas fronteiras (Heite et al., 2013; Kessl e Maurer, 2010). Essas práticas do tratamento, da demarcação e do deslocamento de fronteiras podem ser exemplificadas com relação à fronteira entre trabalho profissional e não profissional (Heite, 2013), à ampliação das possibilidades de ação dos destinatários (Kessl, 2009) ou às análises teóricocorporais. A partir desse pano de fundo, a fronteira se revela em perspectiva analítica como uma categoria que permite reconhecer as (im)possibilidades do ser (diferente) como exclusões contingentes e normativamente plausibilizadas. Deste modo uma perspectiva analítica de fronteiras pode desvelar construções sociopedagógicas da realidade e suas consequências como sendo passíveis de transformação.

\section{Referências}

BUTLER, J. Körper von Gewicht. Frankfurt am Main: Suhrkamp, 1993.

Castel, R. Die Metamorphosen der sozialen Frage: eine Chronik der Lohnarbeit. Konstanz: UVK, 2008.

DOLLINGER, B. Krisenintervention als Aufgabe der Sozialen Arbeit. Zeitschrift für Sozialpädagogik, v. 2, n. 4, p. 377-396, 2004.

DOLLINGER, B. Sozialpädagogische Theorie zwischen Analyse und Zeitdiagnose. Widersprüche, v. 108, p. 31-42, 2008.

DONZELOT, J. Die Ordnung der Familie. Frankfurt am Main: Suhrkamp, 1980.

FORST, R.; GÜNTHER, K. Die Herausbildung normativer Ordnungen: zur Idee eines interdisziplinären Forschungsprogramms. In: R. Forst; K. Günther (Orgs.). Die Herausbildung normativer Ordnungen. Frankfurt am Main: Campus, 2011. p. 11-30.

HEITE, C. Setting and crossing boundaries: professionalization of Social Work and Social Work professionalism. Social Work and Society - special issue Social Work as Working at the Border, p. 1-14, $2013<$ www.socwork.net/sws/index>.

HEITE, C.; KESSL, F.; MAURER, S. Social Work and Society - special issue Social Work as Working at the Border, $2013<$ www.socwork.net/sws/index $>$.

KESSL, F. Soziale Arbeit als Grenzbearbeiterin: einige grenzanalytische Vergewisserungen. In: S. Neumann; P. Sandermann (Orgs.). Kultur und Bildung: neue Fluchtpunkte für die sozialpädagogische Forschung? Wiesbaden: VS Verlag für Sozialwissenschaften, 2009. p. 154-169.

KESSL, F.; MAURER, S. Praktiken der Differenzierung als Praktiken der Grenzbearbeitung: Überlegungen zur Bestimmung Sozialer Arbeit als Grenzbearbeiterin. In: F. Kessl; M. Plösser (Orgs.). Differenzierung, Normalisierung, 
Andersheit: Soziale Arbeit als Arbeit mit den Anderen. Wiesbaden: VS Verlag für Sozialwissenschaften, 2010. p. 154-169.

KLATETZKI, T. Die Fallgeschichte als Grenzobjekt. In: R. Hörster; S. Köngeter; B. Müller (Orgs.). Grenzobjekte: Soziale Welten und ihre Übergänge. Wiesbaden: VS Verlag für Sozialwissenschaften, 2013. p. 117-135.

LAMONT, M.; MOLNÁR, V. The study of boundaries in the Social Sciences. Annual Review of Sociology, v. 28, p. 167-195, 2002.

MESSMER, H. Moralstrukturen professionellen Handelns. Soziale Passagen, v. 4, n. 1, p. 5-22, 2012.

RICHTER, M. Die Sichtbarmachung des Familialen: Gesprächspraktiken in der Sozialpädagogischen Familienhilfe. Weinheim: Beltz Juventa, 2013.

SCHÄFER, A. Zur Kritik pädagogischer Wirklichkeitsentwürfe: Möglichkeiten und Grenzen pädagogischer Realitätsansprüche. Weinheim: Deutscher Studien Verlag, 1989.

SCHÄFER, A. Möglichkeitsräume: von der Rhetorizität des Sozialen und dem polemischen Einsatz des Bildungsversprechens. Vierteljahresschrift für Wissenschaftliche Pädagogik, v. 4, p. 659-679, 2012.

STAR, S. L.; GRIESEMER, J. R. Institutional ecology, 'translation' and boundary objects: amateurs and professionals in Berkeley's Museum of Vertebrate Zoology, 1907-39. Social Studies of Science, v. 19, n. 3, p. 387-420, 1989.

WALLACE, R. J. Konzeptionen der Normativität: einige grundlegende philosophische Fragen. In: R. Forst; K. Günther (Orgs.). Die Herausbildung normativer Ordnungen. Frankfurt am Main: Campus, 2011. p. 33-55.

Autora correspondente:

Catrin Heite

Freiestraße 36

8032 Zurique, Suíça

Recebido em: 20 set. 2013

Aprovado em: 15 out. 2013 